\title{
PERSONALITY TRAITS AND REASONS TO LEAVE COUNTRY IN SERBIAN UNIVERSITY STUDENTS
}

\author{
Jelisaveta Todorovic ${ }^{1}$, Snezana Stojiljkovic ${ }^{1}, \&$ Tamara Ciric $^{2}$ \\ ${ }^{1}$ Department of Psychology, University of Nis (Serbia) \\ ${ }^{2}$ City of Nis government (Serbia)
}

\begin{abstract}
This paper is referring to the problem of brain drain, used to describe 'the situation in which large numbers of educated and very skilled people leave their own country to live and work in another one where pay and conditions are better'. It is why this phenomenon has often been connected to the depletion of the intellectual and professional resources of a country or a region. Serbia has suffered a huge brain drain in recent years. The goal of this research is to examine what are the main reasons of university students to leave Serbia and whether it is possible to find out some personal dispositions for that. In addition, it is important to determine what percentage of students has a wish to go abroad and what are their plans and expectations. The research sample is consisted of 355 students of University of Nis, Serbia. About $62 \%$ of respondents sample was female $(\mathrm{N}=219)$. A questionnaire about students' interests and reasons for going abroad and leave Serbia was prepared by authors for research purposes. Personality traits are defined according to the Big Five model and assessed by The Big Five Inventory - BFI (John \& Srivastava, 1999), intending to measure: extroversion, neuroticism, openness to experience, agreeableness, and conscientiousness. The main results are as following. About $36.2 \%$ of students planned to leave country, $49.2 \%$ of students said that they didn't sure yet, while only $14.6 \%$ didn't show willingness to go abroad and live in foreign country. The most common reasons for going abroad is searching for a work (46\%) and the second one is a wish to continue education (19.7\%). The greatest percentage of students plan to go by the help of scholarship (24.5\%) or by the help of relatives $(21.4 \%)$. Students of different faculties have different levels of priorities when it comes to economic reasons or independence as a reason for going abroad. Some of them are ready to get jobs they would not accept to do in Serbia. Concerning the dimensions of personality, the results showed that primarily high openness to experience and high enough extroversion could be connected to students' willingness to leave their own country. Obtained data are useful for better explanation of strong interest and tendency to go abroad in students' population in Serbia. The findings are discussed in the light of up-to-date literature and studies.
\end{abstract}

Keywords: Brain drain, students, personality traits, reasons for leaving country, Serbia.

\section{Introduction}

This paper is referring to the problem of brain drain, used to describe 'the situation in which large numbers of educated and very skilled people leave their own country to live and work in another one where pay and conditions are better'. During the 1960s and 1970s, this term was used to describe the migration of experts and scientists from underdeveloped regions into developed countries. The term is also used for a widespread phenomenon that students from poor countries go to studies and remain permanently working and living in developed countries. In the region of Southeastern Europe and in Serbia, a high percentage of qualified professionals had left their homeland and employed abroad for a long time, sometimes during the whole working life, and returning after receiving the pension. Several studies have shown that mass migration from Eastern Europe during the 1990s was in fact brain waste, because very few people from those countries found employment that meet their qualifications. It is why this phenomenon has often been connected to the depletion of the intellectual and professional resources of a country or a region.

According to the data collected by The Institute for Sociological Research of the Faculty of Philosophy in Belgrade, during the 1990s about 5\% of the total population of the former Yugoslavia was displaced, which was more than in the previous decades (1971-2.5\% $1981-3.6 \%, 1991-3.9 \%)$. 
Moreover, the majority (91\%) of people were under 40 years, mainly students and graduated people, with more than 13 years of schooling (Grečić, 2010; Grupa 484, 2010). As a consequence of such mass migrations, the vitality of the labor force had been significantly reduced, the inflow of money from foreign exchange was not so great, and the migrants mainly returned as elderly and not healthy enough people. Such a huge migration represents a real devastation in developing countries while developed countries got benefits on the basis of the influx of cheap and qualified workforce.

Going abroad of young educated personnel in order to continue their education and professional development is not only the result of social and historical circumstances in the country. Family and personal parameters can be closely related to emigration. Recent studies discuss whether there is a certain type of personality who is more inclined than others to leave homeland and live abroad.

\section{Research problem and objectives}

The scope and actuality of migration of the Serbian population is basically our motivation to deal with this problem. The goal of this research is to examine what are the main reasons of university students to leave Serbia and whether it is possible to find out some personal dispositions for that.

In addition, our research is aimed to determine what percentage of students show an intention to emigrate, and what are their plans and expectations. We also want to examine how well they are informed about the possibilities and conditions of emigration and living in foreign countries.

\section{Method}

\subsection{Participants}

The sample consisted of 355 students of University of Nis, Serbia, aged 19 to 27 years. About $62 \%$ of respondents sample was female $(\mathrm{N}=219)$ and $38 \%$ was males $(\mathrm{N}=136)$. Respondents are studying the following faculties: Faculty of Electronic Engineering (47), Faculty of Science (47), Faculty of Medicine (33), Faculty of Civil Engineering and Architecture (61), Faculty of Economics (58), Faculty of Philosophy (57), Faculty of Arts (51). Further data will be given to describe the sample of the subjects.

Participants live primarily with both parents in complete families (64\%), and $9.6 \%$ of them live in a single-parent family, due to divorce or death of a father or mother. About $15 \%$ of students live alone or with a roommate, mainly because studying outside their place of residence. $52.4 \%$ of respondents have changed their place of living, whether due to studying or because of migration to larger cities for better living conditions. Respondents are living mainly in town or city $(77.5 \%)$.

The education of the parents of the respondents is predominantly at the secondary level, while a third of them have university education, which is significantly higher than the average educational level of the population in Serbia. More precisely, 50.4\% of fathers finished secondary school, $7.3 \%$ of fathers finished college and $32 \%$ graduated at university; education of mothers is at a similar level: secondary school $54.1 \%$, higher school $5.9 \%$ and university level $29.6 \%$.

Regarding the socio-economic status (SES) of the origin-families, respondents' estimations are as the following: very bad $-2.8 \%$, unsatisfactory $-25.1 \%$, satisfactory $-53.1 \%$, quite well $-17.2 \%$. As can be seen from the data, about $70 \%$ of the respondents consider the socioeconomic situation in the family to be satisfactory or completely good, which indirectly indicates that the unfavorable economic situation is not the only reason they want to go abroad for a shorter or longer period of time. Only $6 \%$ of respondents have a permanent job, and about $14 \%$ of them work occasionally part-time job.

When asked if they have traveled abroad so far, the respondents gave the following answers: $37.7 \%$ rarely travel abroad, occasionally $33.8 \%$, often $11 \%$ and $4.9 \%$ have not traveled yet.

\subsection{Variables and instruments}

A questionnaire about students' interests and reasons for going abroad and emigrate from Serbia was made by authors for research purposes. The questions were designed to examine what are the most frequent reasons for going abroad, for a shorter or longer time: economic reasons, for example, job search, higher incomes and better paid jobs, the possibility of career development and promotion; continuing education and professional development; a quest for adventure and a desire to get to know other cultures; the need for independence and opportunity for personal development. The process of developing the questionnaire is based on the review of the available literature in this field. In terms of content, the questionnaire can be partly compared with aspects of migration from the MBM-Migration Belief Model (Groenewold, Bruijn, \& Bilsborrow, 2012; Hoppe, \& Fujishiro, 2015). Precisely, MBM assumes that emigration intensions and plans are determined by perceived economic threat in the domain of living conditions, perceived emigration benefits, perceived emigration barriers (obstacles in emigration process) and emigration self-efficacy (confidence in one's ability to effectively perform in a foreign country). 
Personality traits are defined according to the Big Five model and assessed by The Big Five Inventory - BFI (John \& Srivastava, 1999), 44-item inventory, intending to measure: extroversion, neuroticism, openness to experience, agreeableness, and conscientiousness. In this conception, personality traits are considered to be time-stable inner dispositions of a person that are able to initiate and direct person's thinking, emotions and behavior. Extroversion vs. introversion (E) refers to person's sociability, activity and excitement-seeking, assertiveness, and positive emotions as warmth and cordiality. Neuroticism vs. emotional stability (N) refers to the negative effects, such as anxiety, hostility, sadness, depression and vulnerability too. Openness vs. closedness to experience $(\mathrm{O})$ refers to person's intellectual curiosity, open-mindedness and novelty seeking, wide interests and imagination. Agreeableness (A) refers to tendency to be trusting, not demanding, altruistic, tender-minded and benevolent in relations with people. Conscientiousness (C) refers to person's dutifulness, achievement striving, tendency to be selfdisciplined, persistent, organized, with strong sense of responsibility to commitments.

\subsection{Procedure}

The survey was conducted in above mentioned faculties, situated in Nis, Serbia. The questionnaires were administered in groups during regular classes, in the period April-June 2016. Testing was anonymous and it took about 40 minutes. Students were informed about the research purposes and their participation was voluntary.

\section{Results and discussion}

\subsection{Reasons, intensions, and emigration plans in university students in Serbia}

For the purposes of this paper, only the most important results of the research will be presented. According to data, $36.2 \%$ of students are planning long-term stay abroad, i.e. to emigrate from Serbia, $49.2 \%$ of students said that they didn't sure yet about that, while only $14.6 \%$ didn't show willingness to go abroad and live in foreign country. The most common reasons for leaving the country are economic: finding jobs, better paid jobs, whether it is in line with professional education of students or less attractive jobs, higher income that enables a better life and the founding of one's own family. It should be emphasized that dissatisfaction with the political situation and the perspective offered to young people for life in the country is also an important motivating factor for the emigration of young people from Serbia.

If we take into consideration both students planning long-term and short-term stay abroad, the goals that students want to achieve by going abroad are: a search for a job of $45.9 \%$; continuing education $19.7 \%$; professional development $9,9 \%$; the desire to get to know other cultures $3.4 \%$; the desire to separate from the parents $1.4 \%$. Students of different faculties have somewhat different priorities when it comes to the goals for going abroad. Besides, some of them are ready to get jobs they would not accept to do in Serbia.

The largest migration of students and professionals is registered in the field of medicine, electronics, and technical sciences which is talked about a lot but there are no precise data; migration is considered to be greater than that recorded in statistical data (Grupa 484,2010; Santric-Milicevic et al., 2014).

Regarding the way students would go abroad, the following results were obtained: expectation that they will receive scholarships - $24.5 \%$, with the help of their relatives - $21.4 \%$, by friends' help $-11 \%$, at own risk - $18 \%$; by a partner's help $-2.8 \%$, getting a job $-3.4 \%$, working on the pool, babysitting etc. $-2,8 \%$.

As can be seen from the above mentioned data, about $70 \%$ of the respondents consider the socioeconomic situation in the family to be satisfactory or completely good, which indirectly indicates that the unfavorable economic situation is not the only reason they want to go abroad for a shorter or longer period of time.

When it comes to informing the students of the University of Niš about going abroad, the data showed the following: only $8.5 \%$ of students are very well informed; $23.4 \%$ of those informed; they know something - 44.8\%; very little information has $19.2 \%$ of students, and $4.2 \%$ are not informed at all.

Bearing in mind the situation in Serbia, characterized by high youth unemployment and unsatisfactory economic situation, it is clear why such a large percentage of youth wants to emigrate and believes that much more opportunities are offered by foreign economically developed countries, in Europe or USA. Although the economic situation in Slovakia is better than in Serbia, recent findings indicate that $23.7 \%$ of Slovak university students planned to emigrate long-term, while $12.3 \%$ of them planned short-time stay abroad, primarily for economic reasons and secondly due to their confidence in one's ability to effectively perform the emigration behavior, called 'emigration self-efficacy' (Dobrowolska-Kulanova, \& Orosova, 2018; Hajduch, Orosova, \& Dobrowolska-Kulanova, 2018). 


\subsection{The role of personality dispositions in the context of migration}

Concerning the dimensions of personality, the results showed that primarily high openness to experience and high enough extroversion could be connected to students' willingness to leave their homeland. Comparing to the university students without emigration intensions, students with emigration plans were scored higher on dimension of openness $(\mathrm{p}<0.01)$ and dimension of extroversion $(\mathrm{p}<0.05)$. Openness to experience relates to intellectual curiosity, a wide range of interests, and openness to change and novelty in general. Accordingly, it's understandable that students of these personality traits show more inclination and readiness to leave their homeland and go to another country. As is well-known, Extroversion refers to person's high involvement in the outside world, the ability to keep interpersonal relations, a tendency to experience positive emotions and an assertive attitude to the social environment. The aforementioned personality dispositions represent the precondition for the person to fit in well in the new environment, to meet the expectations of others and to adapt good enough, and thus show that he/she is able to function adequately in new circumstances.

The finding of an important role of openness in the context of population migration studies is in line with numerous studies conducted around the world as well as in Serbia. Some researchers believe it's possible to talk about a particular type of personality that is prone to migration, so-called "migrant personality" (Boneva, \& Frieze, 2001; Li, Olson, \& Frieze, 2013). That term means that an individual has a personal predisposition for migration and that this decision is not largely conditioned by situational factors, and can manifest in migration from one place to another, but also in the desire to travel for leisure or entertainment and excitement. On the sample of Croatian students, Boneva and Frieze (2001) found that high openness and low "place attachment" are associated with the desire to emigrate. There are also somewhat different views of the essence of migration. "Existential migration" is the term introduced by Madison (2009, according to Luca \& Filipopoulos, 2014), in order to describe a person who has a psychological need to leave home and "explore the world".

Researching the tendencies towards migration to Singapore, on a sample of 1915 young people aged 16 to 26, Chan-Hoong (2008) found that $21 \%$ of young people want to emigrate because of their dissatisfaction with the prospect in their homeland, and they are characterized by openness, high motive of achievement and experiencing self-efficacy. On the other hand, about $23 \%$ of youth didn't want to go abroad because of high conservatism and strong attachment to family and nation, and that could be seen as cultural resilience. In a survey conducted in America on a sample of 2,772 students abroad (Salisbury at all, 2008), it was found that the decision to go to study outside the country is influenced by social, cultural, financial and personal factors that are accumulating since high school. Factors that contribute to the decision of young people to leave are: higher socioeconomic status of the family, higher educational level of parents, school success, as well as openness to differences, for new ideas and experiences.

The Office for cooperation with the Diaspora of the City of Nis (South East Serbia) conducted a survey in February 2014 on the sample of students of the upper secondary school, aiming to examine how many young people tend to study and work outside Serbia, what are the most important reasons for going to abroad, what are their personality traits and what kind of families they live in (Ćirić, Sinđić and Matković, 2014). The main results are as following: students who wish to study abroad are open-minded persons, with wide interest to get know new culture and people, they are successful in school, not satisfied with socioeconomic status of families living in.

\section{Implications and future research direction}

Findings indicate that high percentage (more than $30 \%$ ) of university students from the sample show emigration intentions and plan long-term staying abroad. The economic and political situation in state and lack of possibilities to get an adequate and well paid job are the most frequent reasons for emigration among students. The second motive to go abroad is related to professional development and educating purposes. Openness and wish to get to know some other cultures is the third reason for leaving Serbia, but it's not frequent. Concerning personality dimensions, students' high openness to experience and high enough extroversion could be connected to students' willingness to emigrate and leave their homeland. Accordingly, that finding may be seen partly in line with concept of 'migrant personality' but more profound research is needed in the future. Furthermore, broader coverage of personality variables are desirable; thus, the level of aspiration, motive of achievement, expectations of living abroad, and life philosophy of the person should be included.

It's worthy to make some concluding remarks in the context of research problem in general. Many academics and successful professionals, mainly young adults, apply for a job abroad and sometimes decide to live as emigrants in foreign countries with no intention to return to homeland. Having in mind that university students, graduated persons and professionals represent the most potent 
part of general population (they are young, skillful and high educated persons), there are a lot of reasons to worry about the future in Serbia.

According to the data, about $68 \%$ of respondents have been poorly informed about the way of going abroad and living conditions in foreign countries. It is therefore important to improve information through providing accurate and reliable information on opportunities and benefits, but also on the risks of emigration. This would not directly prevent the migration of young people and professionals, but it could contribute to making the decision based on reliable and verified information.

Migration for employment and schooling is nowadays a very widespread process in the world, but this is a much bigger problem for a small and economically underdeveloped country such as Serbia. It is crucial to stimulate the return of young people to their country or to develop good business cooperation with successful professionals, and in this way, at least partially reduce the adverse effects of mass migrations.

\section{Acknowledgments}

This paper was created as a part of the research project No. 179002, supported by the Ministry of Education, Science and Technological Development, Republic of Serbia, and within the scope of project supported by Faculty of Philosophy, University of Nis, Serbia, No. 183/1-16-9-01

\section{References}

Boneva, B. S., \& Frieze, I. H. (2001). Toward a concept of migrant personality. Journal of Social Issues, $57,477-491$.

Chan-Hoong, L. (2008). Attitudes on emigration among young Singaporeans. National University of Singapore: Working Paper No. 19.

Ćirić, T., Sinđić, M., Matković, J. (2014). Osobine ličnosti i porodični odnosi maturanata koji imaju tendenciju da studiraju ili rade van Republike Srbije. 62. Sabor psihologa Srbije, Knjiga rezimea /Book of abstracts, 27-28. Beograd: CPP.

Dobrowolska-Kulanova, M., \& Orosova, O. (2018). Students' emigration intensions and emigration plans in the context of the Migration Belief Model. In C. Pracana \& M. Wang (Eds.) Psychology Applications and Developments IV (178-187). Lisboa, Portugal: InScience Press.

Grečić, V. (2010). Srpska naučna dijaspora. Beograd: Institut za međinarodnu politiku i privredu.

Groenewold, G., Bruijn, B., \& Bilsborrow, R. (2012). Psychosocial factors of migration: Adaptation and application of the health belief model. International Migration, 50 (6), 211-231.

Grupa 484 (2010). Odliv mozgova iz Srbije - problemi i moguća rešenja /Brain drain in Serbia problems and possible solutions/ www.researchgate.net/publictopics.PublicPostFileLoader.html

Hajduch, B., Orosova, O., \& Dobrowolska-Kulanova, M. (2018). Factors related to life satisfaction, cultural resilience and emigration intensions among Slovak university students. In C. Pracana \& M. Wang (Eds.) Psychology Applications and Developments IV (87-95). Lisboa, Portugal: InScience Press.

Hoppe, A., \& Fujishiro, K. (2015). Anticipated job benefits, career aspiration, and generalize self-efficacy as predictors for Migration decision-making. International Journal of Intercultural Relations, 47, 13-27.

John, O. P, \& Srivastava, S. (1999). The Big-Five trait taxonomy: History, measurement, and theoretical perspectives. In L.A. Pervin \& O.P. John (Eds.), Handbook of personality: Theory and research (Vol.2, pp. 102-138). New York: Guilford Press.

Li, M., Olson, J., \& Frieze, I. (2013). Students' Study Abroad Plans: The Influence of Motivational and Personality Factors. Frontiers: The Interdisciplinary Journal of Study Abroad, 23, 73-87.

Luca, M. \& Filipoppoulos, P. (2014). Motivational and adaptation experiences of returnees and migrants to Cyprus: A grounded theory study with Counselling Psychology application and practice implications in Europe. The European Journal of Counselling Psychology, Vol. 3(1), 20-41.

Salisbury, M., Umbach, P., Paulsen, M., Pascarella, E. (2008). Going Global: Understanding the Choice Process of the Intent to Study Abroad. Research in Higher Education Journal. DOI 10.1007/s11162-008-9111-x.

Santric-Milicevic, M. M., Terzic-Supic, Z. J, Matejic, B. R., Vasic, V., Ricketts III, T. C. (2014). First- and fifth-year medical students' intentions for emigration and practice abroad: A case study of Serbia. Health Policy, 118(2), 173-183. 